\title{
Prevalence of Psychosomatic Disorders Among Dental Students with Recurrent Aphthous Stomatitis. A Cross-Sectional Study.
}

Saud Fahad Al Hazzaa ( $\sim$ facsmax7921@gmail.com )

Department of Oral Medicine and Radilogy Central Security Hospital

Research

Keywords: Psychosomatic disorders, RAS, DASS 21, Dental Students, Depression, Anxiety, Stress

Posted Date: August 26th, 2020

DOI: https://doi.org/10.21203/rs.3.rs-52851/v1

License: (1) (1) This work is licensed under a Creative Commons Attribution 4.0 International License.

Read Full License 


\section{Abstract}

\section{Aims}

To determine the prevalence of psychosomatic disorders among dental students with recurrent aphthous stomatitis.

\section{Method}

A cross-sectional study was performed on 184 dental students with recurrent aphthous stomatitis (RAS). A p-value cut off point of 0.05 at $95 \%$ confident interval $(\mathrm{Cl})$ was used to determine statistical significance. Descriptive and inferential statistics were conducted where frequency and proportion were used, to present all categorical variables. Depression, Anxiety, Stress Scale questionnaires were used to assess the depression, anxiety, and stress of RAS dental students. The analysis assessed the relationship between RAS among socio-demographic characteristics of depression, anxiety, and stress by using a chisquare test.

\section{Results}

The prevalence of depression was dominant among dental students at $62.5 \%$. More than half of the respondents (58.2\%) were anxious, whereas the prevalence of stress was lower i.e. $40.2 \%$. There was no significant relationship found between depression and RAS $(p>0.05)$.

\section{Conclusion}

Age group in years and number of ulcers in each occurrence were statistically associated for anxiety and stress, and gender was also significant to anxiety. There was no significant relationship found between depression and RAS.

\section{Introduction}

Body and mind complement each other and work as a unit. Most diseases are psychosomatic and involve the mind and body. Each physical disease has a mental component, and how an individual reacts and copes with it varies significantly. ${ }^{1,2}$ The mouth signifies an organ of the expression of certain "instinctional" cravings and is charged with a high psychologic potential. The direct or indirect expression of emotions or conflicts may be the cause of certain diseases that affect the oral mucosa. Oral diseases with psychosomatic etiology have long been known in medicine, and mental or emotional factors may act as risk factors that may influence the beginning and development of oromucosal diseases. ${ }^{3,4,5}$

The relationship between the two is explained by two hypotheses: (1) A specific hypothesis states that expression of a predetermined disease or illness occurs due to a certain stimulus or conflicts or stressors. The heightened response of the body that persists even after the cessation of a stimulus evoked the change and eventually results in a disease. (2) A nonspecific hypothesis states that generalized stress 
creates preconditions for a number of not necessarily predetermined diseases. According to this hypothesis, four varieties of reactions occur due to stress viz., healthy normal, neurotic, psychotic, and psychosomatic. $^{4}$

Many authors have explained that life exists by maintaining homeostasis that is constantly confronted by intrinsic and extrinsic forces such as stressors. Favorable conditions improve the growth, development, and survival of the species. By contrast, the beginning of stress occurs during threatening situations, which are beyond the normal control of an individual, and may cause in dysphoria and finally emotional or somatic disease. ${ }^{6,7,8}$ The stress response triggers the autonomic nervous system, mostly sympathetic, through the hypothalamic-pituitary-adrenal (HPA) axis, which secretes corticotropinreleasing factor (CRF) and arginine-vasopressin (AVP), leading to release of adrenocorticotrophic hormone (ACTH), enkephalins, and endorphins. Thus, the stress-response function acts through a positive, bidirectional feedback loop. ${ }^{9} \mathrm{CRH}$ and AVP are secreted in a circadian, pulsatile manner with approximately 2 to 3 secretory episodes per hour in non-stressful situations. In resting conditions, it peaks in early morning and progressively decreases as the day progresses. Diurnal variations are disrupted during stressful situations. The pulsations of $\mathrm{CRH}$ and AVP are improved during acute stress, resulting in increased ACTH and cortisol. Various other factors are also released in response to stress, such as angiotensin II, various cytokines, and lipid mediators of inflammation, which act on various components of the HPA axis, potentiating its activity. ${ }^{10}$

Therefore, the aim of the study is to determine the prevalence of psychosomatic disorders among dental students with recurrent aphthous stomatitis and its level of association.

\section{Materials And Methods}

\section{Ethical Approval}

The study was registered with the research center, and ethical approval was obtained from the institutional review board (IRB) of Riyadh Elm University (REU). The research registration number was FPGRP/43737001/267.

\section{Study Population}

The cross-sectional study targeted the dental students registered at Riyadh Elm University (REU) at all levels (undergraduate, post graduate, and interns). For this, a structured questionnaire was sent randomly by email to all targeted population. The number of respondents was 184 , and the response rate was $73.6 \%$.

The exclusion criteria were subjects with special needs, pregnant women, epileptic subjects, subjects with a clinical history of psychosomatic alterations or treatment with psychoactive drugs, and individuals with history of oral surgery (except exodontia, implants, and impactions). 


\section{Data collection}

Informed consent form and electronic questionnaire were distributed randomly by official administration email through the postgraduate office of REU. The questionnaires had three sections. The first section included demographic data including age, gender, education level, marital status. The second section contained personal information and questions related to Recurrent Aphthous Stomatitis (RAS) ${ }^{11}$ In RAS section, the subjects were asked to report the time of last ulcer experience, the frequency of the ulcer, the number of ulcers in each occurrence, and to determine the area of occurrence.

The third section evaluated the aspects of depression, anxiety, and stress applying the Depression, Anxiety, Stress Scale (DASS 21). ${ }^{12}$ The DASS 21 is a 21 -item self-report questionnaire designed to measure the severity of a range of symptoms common to both depression, anxiety, and stress. The essential function of the DASS is to assess the severity of the core symptoms of depression, anxiety, and stress. Many studies among different populations confirmed that the DASS is comprehensible and sensitive to detecting common mental disorders ${ }^{13}$, and is a reliable and valid method of assessing features of depression, anxiety, and tension-stress ${ }^{14}$.

\section{Statistical analysis}

The data analysis was performed by using Statistical Packages for Social Sciences version 21.Level of significance was set at $<0.05$. Descriptive and inferential statistics were used. Frequency and proportion were used to present all categorical variables. DASS 21 was used as questionnaires to assess the depression, anxiety, and stress of dental students with RAS. Based on the given criteria, the answer options for each question was from $0=$ Did not apply to me at all, $1=$ Applied to me to some degree or some of the time, 2 = Applied to me to a considerable degree, or a good part of time, $3=$ Applied to me very much, or most of the time.

DASS 21 was divided into three equal parts for depression, anxiety, and stress (seven questions each), each predictor has an equal total score of 21 points, and the summed score was multiplied by 2 to obtain a total score of 42 points $^{12}$. Normal categories (not depressed, not anxious, not stressed) were classified by the score range of 0 to 9 and categories with a mental disorder (depressed, anxious, stressed) were classified by the score range of 10 to 42 or from mild to extremely severe. The analyses assessed the relationship between RAS among sociodemographic characteristics and DAS by using a chi-square test.

\section{Results}

There were 184 dental students that voluntarily enrolled in this study. Age range was from 20 to 54 year. Of the 184 respondents, $55.4 \%$ were female and the remainder was males. Of the participants, $37 \%$ were post graduate students, followed by clinical level students $(28.8 \%)$, interns $(17.4 \%)$, and pre-clinical students $(16.8 \%)$. The majority of the group were single (64.1\%) compared with married $(35.9 \%)$. Regarding time of last ulcer, $57.1 \%$ occurred more than 6 months previously, $9.8 \%$ occurred 6 months 
previously, $12 \%$ occurred within the last 3 months, $12.5 \%$ occurred in the previous month, and $8.7 \%$ presently occurred. Many respondents had recurrence of ulceration once in more than 6 months previously (66.3\%), followed by once in 6 months previously (13.6\%), and the remaining had a single recurrence once in 3 months and once in 1 month. Additionally, 79.9\% of the respondents had a one-time recurrence, $13 \%$ had a recurrence three to six times, and $7.1 \%$ had a recurrence more than six times, and the most common areas in ascending order were lips, cheek, gingiva, and tongue, including multiple areas (Table 1).

The prevalence of DAS among dental students is presented in (Table 2). Based on the DASS 21 assessment, the majority of the respondents had normal results for depression, anxiety, and stress (Fig. 1). Notably, depression was dominant among dental students and accounted for 115 (62.5\%), and no depression was relatively less, 69 (37.5\%). The criteria for anxiety was identical to that of depression (anxious $=10-42$, not anxious $=0-9$ points) and the result revealed that more than a half of the respondents were anxious $58.2 \%$ (107) compared with not anxious with $41.8 \%$ (77), whereas the prevalence of stress followed the same pattern (stressed $=10-42$, not stressed $0-9$ points) where it was found that "stressed" was lower, 74 (40.2\%), compared to "without stress", 110 (59.8\%).

In the relationship between DAS among sociodemographic characteristics and RAS, a significant difference was found at the level of anxiety ( $\mathrm{p}-0.029)$ and level of stress ( $\mathrm{p}-0.026)$ among age groups in years, but no statistical difference on level of depression ( $p-0.0236)$ was observed. Gender was statistically significant at the level of anxiety ( $\mathrm{p}-0.004)$; however, no relationship was found at level of depression ( $p-0.193)$ and level of stress ( $p-0.132)$. Number of ulcers in each occurrence shows a significant relationship for level of anxiety ( $p-0.014)$ and level of stress ( $p-0.007)$ but negative for the level of depression ( $p-0.077)$. There was also found a negative relationship at the level of DAS for the following variables: educational level, marital status, time of last ulcer, and frequency of ulceration (Table 3).

\section{Discussion}

The current study investigated RAS and its association with psychosomatic disorders. The findings have thus contributed to articles that have investigated the phenomena of this oral mucosal condition. Contemporary lietrautre have associated RAS with different symptoms and with psychological factors. In this study, we aimed to analyze psychological factors and how they affected patients with RAS; thereby establishing the level of association between RAS and Psychosomatic disorder.

\section{Depression Associated with RAS}

Some investigators have theorized that stress during student life is a major factor in RAS, although the difference in age groups should be considered as well ${ }^{15}$. Depression, anxiety, and stress (DAS) are psychosomatic disorders that have a significant influence on RAS are elaborated on in this study. Incidence of depression among dental students in this study was high (62.5\%). The prevalence of 
depression among patients with RAS had also been discussed ${ }^{16,17,18}$. Ajmal et.al. ${ }^{16}$ published "Prevalence and Psychological Stress in Recurrent Aphthous Stomatitis among Female Dental Students in Saudi Arabia." and analyzed depression and anxiety of dental students using the Hospital Anxiety and Depression Scale (HADS) questionnaire. They reported that $65 \%$ of the students had depression, which was comparable to the finding in this study.

\section{Anxiety Associated with RAS}

Moreover, another crucial member of psychosomatic illness is anxiety. In this study, more than half of the respondents were anxious, $58.2 \%$. This finding is consistent with papers published locally and abroad ${ }^{17-}$ ${ }^{24}$. The highest rates of anxiety disorder among patients with RAS was reported by Ajmal et.al. ${ }^{16}$ They reported $88 \%$ of the female dental students were suffering from anxiety, which was far off distant compared with the finding of this study. Notably, a study from Croatia registered the lowest prevalence of anxiety, $26.5 \% .{ }^{19}$ Additionally, Alrashdan and Alkhader ${ }^{21}$ observed that patients with persistent RAS often had elevated anxiety levels.

\section{Stress Associated with RAS}

Stress resulting from student life may be the precipitating factor for the higher prevalence of RAS in a cohort of professional students. ${ }^{25}$ The prevalence of stress in this study was $40.2 \%$, which was lower than in those without stress. Articles on the same subject have discussed stressful events in various forms. ${ }^{21-28}$ The highest incidence of stress among patients with RAS was recorded by Ajmal et.al. ${ }^{16}$ They reported that $90 \%$ of patients with RAS were exposed to stress. The present paper is in agreement with Gavic et.al. ${ }^{19}$ They reported that $44.1 \%$ of the patients with RAS reported stress.

Huling et.al. ${ }^{26,27}$ have related RAS to stressful events. Al Rashdan and Al khader ${ }^{21}$ remarked that experiencing a stressful life event increased the incidence of an RAS episode by almost three times, and mental stressors had a larger effect than physical stressors on the occurrence of RAS episodes.

\section{Measurement of Psychosomatic Disorder among patients with RAS}

Psychosomatic disorder is one of the most significant factors that influenced patients with RAS. Psychosomatic disorder affects physical and mental health and could affect the progression of oral mucosal disorders. Many studies have demonstrated that in most of the oral problems such as chronic pain disorders, BMS, and RAS, mental health plays a vital role in their pathogenesis. Thus, mental state evaluation is necessary to assess if oral illness is affecting the physical and emotional being of the patient. This study measured the psychosomatic disorder of patients with RAS by using (DASS) 21 questionnaires ${ }^{12}$ because this scale measures and assesses three types of psychosomatic disorders (depression, anxiety, and stress) simultaneously.

\section{Limitations}


The generalization of this study is subject to limitations. First, the findings could be more beneficial if the associated diseases were indicated in a specific manner, similar to the aforementioned articles, adding to the substantiality of this paper. Second, to create a comprehensive overview of psychosomatic disorder and its effect on patients with RAS, adding more variables in the baseline characteristics would be ideal, such as RAS duration and number of RAS episodes. Last, increasing the sample size would indicate be most changes, because this would provide significant results that could provide additional information regarding the phenomena of this study subject because in any study of this type the higher the number of study subjects, the higher the power of study to detect significant changes.

\section{Conclusions}

More than half of the dental students with RAS were either depressed or anxious; with the incidence of stress being considerably less than that. Age group in years and number of ulcers in each occurrence were statistically associated with anxiety and stress, and gender was also a significant factor for anxiety. However, this paper found no significant relationship between depression and RAS. This finding does not exclude the possibility that depression and anxiety are the most influential factors in patients with RAS. In this regard, this issue must be addressed in future studies to further manage the development of RAS where a specialist in psychosomatic disorders plays a vital role in coping with this type of disorder. In the management of RAS, traditional and conventional methods could be used to shorten the duration of the healing time or at least temporarily relieve pain.

\section{Declarations}

\section{Acknowledgements:}

Not applicable.

\section{Authors' contributions:}

The whole study was done by SFAH

\section{Funding:}

Not applicable.

\section{Availability of data and material:}

The data sets examined for this study are available from the corresponding author upon reasonable request.

\section{Ethics approval and consent to participate:}


The ethical approval was obtained from the institutional review board (IRB) of Riyadh Elm University (REU). The research registration number was FPGRP/43737001/267.

\section{Consent for publication:}

Not applicable.

\section{Competing interests:}

The author declare that he has no competing interest.

\section{References}

1. Lachman, J,L. (1972). Psychosomatic Disorders- A Behavioristic Interpretation. New York. John Wiley Publishers. pp. 2 - 4.

2. Jones, J.H., and Mason, D.K. (1990). Oral Manifestations of Systemic Disease. 2nd ed. London: Bailliere Tindall. p. 30-60.

3. Richter, I., Vidas, I., and Turčinović, P. (2003). Relationship of psychological characteristics and oral diseases with possible psychosomatic aetiology. Acta Stomat Croat. 37, pp. 35-9.

4. Nagabhushan, D., Rao, B.B., Mamatha, G.P., Annigeri, R., and Raviraj, J. (2004). Stress related oral disorders- A review. J Indian Acad Oral Med Radiol. 16, pp. 197-200.

5. Sanadi, R.M., and Vandana, K.L. (2005). Stress and its implications in periodontics- A review. J Indian Acad Oral Med Radiol. 17, pp. 8-10.

6. Chrousos, G.P. (1992). Regulation and dysregulation of the hypothalamic-pituitary-adrenal axis: The corticotropin releasing hormone perspective. Endocrinol Metab Clinics North Am. 21, pp. 833-58.

7. Chrousos, G.P., and Gold, P.W. (1992). The concepts of stress system disorders. Overview of behavioral and physical homeostasis. JAMA. 267, pp. 1244-52.

8. Tsigos, C., and Chrousos, G.P. (1994). Physiology of the hypothalamic-pituitary-adrenal axis in health and dysregulation in psychiatric and autoimmune disorders. Endocrinol Metab Clin North Am. 23, pp. 451-66.

9. Reiche, E.M., and Nunes, S.O. (2004). Morimoto HK. Stress, depression, the immune system, and cancer. Lancet Oncol. 5, pp. 617-25.

10. Tsigos, C., and Chrousos, G.P. (2002). Hypothalamic-pituitary-adrenal axis, neuroendocrine factors and stress. J Psychosom Res. 53, pp. 865-71.

11. Shiny George, Biju Baby Joseph (2016) A Study on Aphthous Ulcer and its Association with Stress among Medical Students of an Indian Medical Institution , International Journal of Contemporary Medical Research 2016;3(6):1692-1695.

12. Lovibond, S.H., and Lovibond, P.F. (1995). Manual for the Depression Anxiety Stress Scale. Sydney: Psychology Foundation. 
13. Thach Duc Tran , Tuan Tran1 and Jane Fisher .(2013) Validation of the depression anxiety stress scales (DASS) 21 as a screening instrument for depression and anxiety in a rural community-based cohort of northern Vietnamese women. BMC Psychiatry J 2013, 13:24

14. Martin M. Antony; Bieling ; Swinson ;Cox and Enns (1998) , Psychometric Properties of the 42-Item and 21-Item Versions of the Depression Anxiety Stress Scales in Clinical Groups and a Community Sample, The American Psychological Association, Inc.1040-3590/98/5300

15. Chavan, M., Jain, H., Diwan, N., Khedkar, S., Shete, A., and Durkar S. (2012). Recurrent aphthous stomatitis: a review. J Oral Pathol Med. doi: 10.1111/j.1600-0714.2012.01134.x.

16. Ajmal, M., Ibrahim, L., Mohammed, N., and Al-Qarni H. (2018). Prevalence and Psychological Stress in Recurrent Aphthous Stomatitis Among Female Dental Students in Saudi Arabia. Clujul Medical Vol. 91, No. 2, pp. 216-221.

17. Pakfetrat, A., Delavarian, Z., Rasekhi, J., Seyyedi, A., and Salah, S. (2014). Psychological Assessment of Patients with Oral Aphthous Ulcers. Journal of Islamic Dental Association of IRAN (JIDAI) Autumn 2014, 26, (4).

18. Dangore, S. (2016). Association of Oral Health with Psychological Health. Indian Journal of Research. 5(11).

19. Gavic, L., Cigic, L., Lukenda, D.B., Gruden, V., and Pokupec, J.S.G. (2014). The role of anxiety, depression, and psychological stress on the clinical status of recurrent aphthous stomatitis and oral lichen planus. J Oral Pathol Med, 43, pp. 410-417.

20. Polat, C., Düzer, S., Ayyıldız, H., Seç, S., Aksoy, N., Sakalıığlu Ö, Akyiğit, A., and Çetiner, H. (2018). Association Between Anxiety, Depression, and Salivary Cortisol Levels in Patients with Recurrent Aphthous Stomatitis Turk Arch Otorhinolaryngol, 56(3), pp. 166-9.

21. Alrashdan, M.S., and Alkhader, M. (2017). Psychological factors in oral mucosal and orofacial pain conditions. Eur J Dent, 11, pp. 548-52.

22. Rezaei, F., Aminian, M., and Raygani, A.V. (2017). Evaluation of salivary cortisol changes and psychological profiles in patients with recurrent aphthous stomatitis. Contemp Clin Dent, 8, pp. 25963.

23. Ge, L. (2017). Healthy lifestyle habits benefit remission of recurrent aphthous stomatitis and RAS type ulceration. British Dental Journal. DOI: 10.1038/sj.bdj.2018.38.

24. Nadendla, L, K., Meduri, V., Paramkusam, G., and Pachava, K.R. (2015). Relationship of salivary cortisol and anxiety in recurrent aphthous stomatitis. Indian Journal of Endocrinology and Metabolism.19(1).

25. Miller, M.F., and Ship, I.I. (1977). A retrospective study of the prevalence and incidence of recurrent aphthous ulcers in a professional population, 1958-1971. Oral Surg Oral Med Oral Pathol, 43, pp. $532-7$.

26. Huling, L.B., Baccaglini, L., Choquette, L., Feinn, R. S., and Lalla, R.V. (2012). Effect of Stressful Life Events on the Onset and Duration of Recurrent Aphthous Stomatitis. J Oral Pathol Med. 41(2), pp. 149-152. doi:10.1111/j.1600-0714.2011.01102.x. 
27. Huling, L.B., Baccaglini, L., Choquette, L., Feinn, R.S., and Lalla, R.V. (2013). Stress associated with onset of recurrent aphthous stomatitis Evidence-Based Dentistry, 14, pp. 25. doi:10.1038/sj.ebd.6400919.

\section{Tables}


Table 1

Sociodemographic characteristics of and recurrence of ulceration in the study group

\begin{tabular}{|c|c|}
\hline Study Variables & $\begin{array}{l}N(\%) \\
(n=184)\end{array}$ \\
\hline \multicolumn{2}{|l|}{ Age group in years } \\
\hline$\cdot \leq 25$ years old & $101(54.9 \%)$ \\
\hline$\cdot>25$ years old & $83(45.1 \%)$ \\
\hline \multicolumn{2}{|l|}{ Gender } \\
\hline - Male & $82(44.6 \%)$ \\
\hline - Female & $102(55.4 \%)$ \\
\hline \multicolumn{2}{|l|}{ Educational Level } \\
\hline - Pre-clinical level & $31(16.8 \%)$ \\
\hline - Clinical level & $53(28.8 \%)$ \\
\hline - Intern & $32(17.4 \%)$ \\
\hline - Post graduate & $68(37.0 \%)$ \\
\hline \multicolumn{2}{|l|}{ Marital Status } \\
\hline - Single & $118(64.1 \%)$ \\
\hline - Married & $66(35.9 \%)$ \\
\hline \multicolumn{2}{|l|}{ Time of last ulcer } \\
\hline - Experiencing presently & $16(08.7 \%)$ \\
\hline - Occurred last 1 month & $23(12.5 \%)$ \\
\hline - Occurred last 3 months & $22(12.0 \%)$ \\
\hline - Occurred last 6 months & $18(09.8 \%)$ \\
\hline - Occurred more than 6 months & $105(57.1 \%)$ \\
\hline \multicolumn{2}{|l|}{ Frequency of ulceration } \\
\hline - Once in a month & $16(08.7 \%)$ \\
\hline - Once in 3 months & $21(11.4 \%)$ \\
\hline - Once in 6 months & $25(13.6 \%)$ \\
\hline - Once in more than 6 months & 122 (66.3\%) \\
\hline
\end{tabular}

Page $11 / 13$ 


\begin{tabular}{|ll|}
\hline Study Variables & $\begin{array}{l}\mathbf{N}(\%) \\
(\mathbf{n}=184)\end{array}$ \\
\hline Number of ulcer in each occurrence & \\
\hline$\cdot$ One time & $147(79.9 \%)$ \\
\hline$\cdot 3-6$ times & $24(13.0 \%)$ \\
\hline$\cdot>6$ times & $13(07.1 \%)$ \\
\hline Area of occurrence & \\
\hline$\cdot$ Cheek & $41(22.3 \%)$ \\
\hline$\cdot$ Gums & $32(17.4 \%)$ \\
\hline$\cdot$ Lips & $61(33.2 \%)$ \\
\hline$\cdot$ Tongue & $21(11.4 \%)$ \\
\hline$\cdot$ Multiple areas & $29(15.8 \%)$ \\
\hline
\end{tabular}

Table 2

Prevalence of DAS among patients with RAS

\begin{tabular}{|ll|}
\hline Factor & $\begin{array}{l}\mathbf{N}(\%) \\
(\mathbf{n}=184)\end{array}$ \\
\hline Depression & $115(62.5 \%)$ \\
\hline - Depressed & $69(37.5 \%)$ \\
\hline - Not depressed & \\
\hline Anxiety & $107(58.2 \%)$ \\
\hline - Anxious & $77(41.8 \%)$ \\
\hline - Not anxious & \\
\hline Stress & $74(40.2 \%)$ \\
\hline - Stressed & $110(59.8 \%)$ \\
\hline - Not stressed & \\
\hline DAS - Depression, Anxiety, Stress; RAS - Recurrent Aphthous Stomatitis \\
\hline
\end{tabular}


Table 3

Relationship between DAS among sociodemographic characteristics and RAS $(\mathrm{n}=184)$

\begin{tabular}{|lllllll|}
\hline & \multicolumn{2}{l}{ Level of Depression } & \multicolumn{2}{l|}{ Level of Anxiety } & \multicolumn{2}{l|}{ Level of Stress } \\
\hline \multirow{2}{*}{ Factor } & Depressed & ND & Anxious & NA & S & NS \\
& $N(\%)$ & $N(\%)$ & $N(\%)$ & $N(\%)$ & $N(\%)$ & $N(\%)$ \\
& $(n=115)$ & $(n=69)$ & $(n=107)$ & $(n=77)$ & $(n=74)$ & $(n=110)$ \\
\hline
\end{tabular}

$\mathrm{N}=$ Depressed $\quad \mathrm{ND}=$ Not Depressed

\section{Figures}

Figure 1: Distribution of DAS

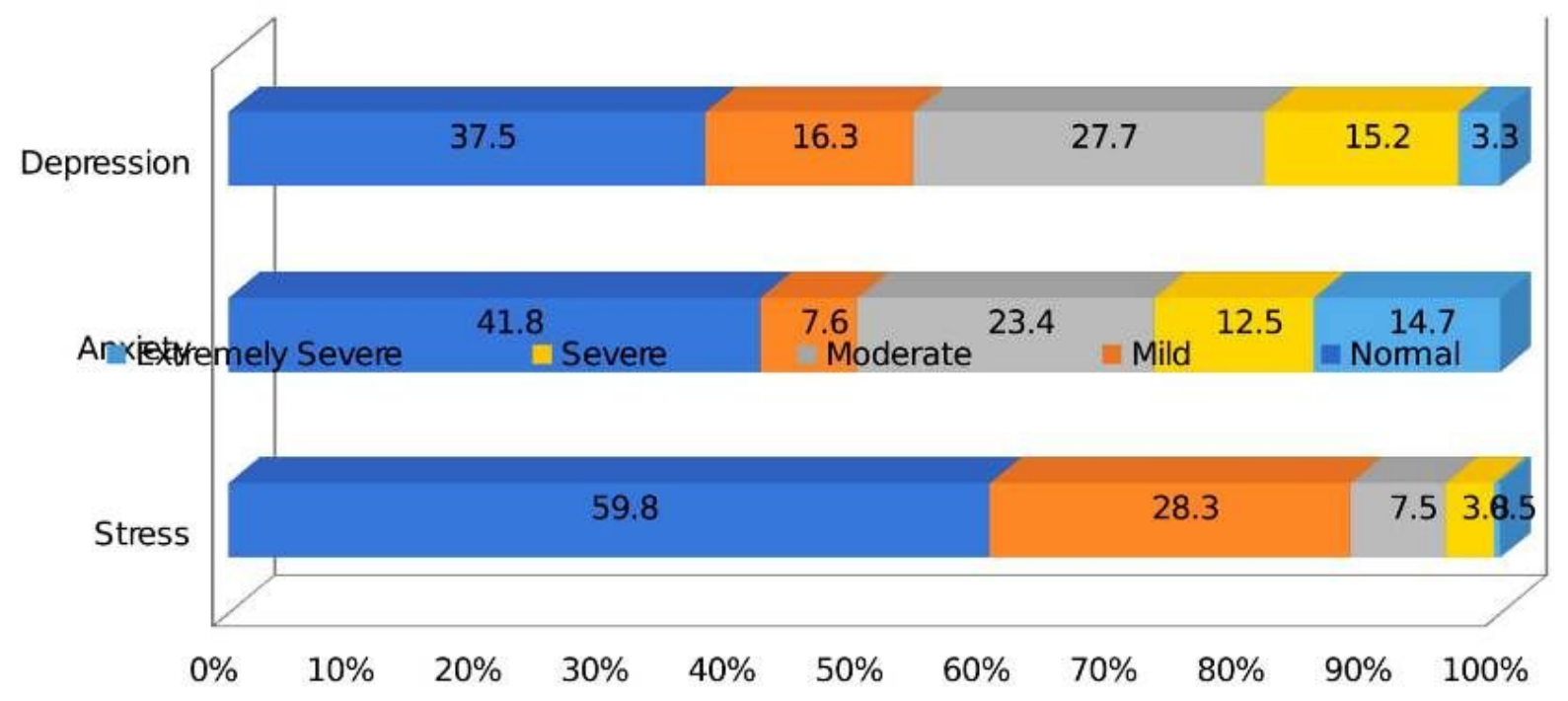

Figure 1

Illustrates the distribution of DAS among the students. 